\title{
Recovery of Ammonium Salt from Nitrate-Containing Water by Iron Nanoparticles and Membrane Contactor
}

\author{
Yuhoon Hwang ${ }^{1 \dagger}$, Dogun Kim ${ }^{2}$, Yong-Tae $\mathrm{Ahn}^{3}$, Chung-Man Moon ${ }^{4}$, Hang-Sik Shin ${ }^{1}$ \\ ${ }^{1}$ Department of Civil and Environmental Engineering, KAIST, Daejeon 305-701, Korea \\ ${ }^{2}$ Department of Civil Engineering, Kyung Hee University Global Campus, Yongin 446-701, Korea \\ ${ }^{3}$ Department of Civil and Environmental Engineering, The Pennsylvania State University, University Park, PA 16802, USA \\ ${ }^{4}$ Department of Civil and Environmental Engineering, University of Windsor, Windsor, ON, Canada
}

\begin{abstract}
This study investigates the complete removal of nitrate and the recovery of valuable ammonium salt by the combination of nanoscale zero-valent iron (NZVI) and a membrane contactor system. The NZVI used for the experiments was prepared by chemical reduction without a stabilizing agent. The main end-product of nitrate reduction by NZVI was ammonia, and the solution pH was stably maintained around 10.5. Effective removal of ammonia was possible with the polytetrafluoroethylene membrane contactor system in all tested conditions. Among the various operation parameters including influent $\mathrm{pH}$, concentration, temperature, and contact time, contact time and solution $\mathrm{pH}$ showed significant effects on the ammonia removal mechanism. Also, the osmotic distillation phenomena that deteriorate the mass transfer efficiency could be minimized by pre-heating the influent wastewater. The ammonia removal rate could be maximized by optimizing operation conditions and changing the membrane configuration. The combination of NZVI and the membrane contactor system could be a solution for nitrate removal and the recovery of valuable products.
\end{abstract}

Keywords: Ammonia removal, Membrane contactor, Nano zero-valent iron, Nitrate reduction Polytetrafluoroethylene membrane

\section{Introduction}

Nitrogen is an essential element for living creatures. However, an excess of nitrogen from various sources can cause environmental problems such as eutrophication. Furthermore, when nitrogen compounds enter environmental water in the form of nitrate, they contaminate drinking water sources [1].

Nitrate is removed through various technologies including ion exchange, reverse osmosis, biological denitrification, and chemical reduction [2-5]. However, ion exchange and reverse osmosis require frequent regeneration of the media and generate secondary brine waste. Biological denitrification, the most widely used method, requires intensive maintenance and a constant supply of organic substrates. Moreover, the microbial processes are generally slower and sometimes less complete than chemical reduction. Of the various chemical reduction methods proposed for the effective removal of nitrate, zero-valent iron (ZVI) has attracted the most interest. The use of nanoscale zero-valent iron (NZVI) has several advantages over microscale ZVI, particularly in terms of its high level of stable reactivity [6].

However, the end-product of this reaction is sometimes unfavourable. We conducted a previous study on the final product of nitrate reduction, and ammonia, which is undesirable, was the main end product [7]. Therefore, it is required to consider further treatment for complete removal of the ammonia produced.

Recently, membrane contactors have been considered as an attractive alternative for the removal of volatile contaminants such as ammonia [8]. Membrane contactors allow direct contact and mass transfer between gaseous and liquid phases without dispersing one phase into the other [9].

Compared to conventional air stripping, ammonia stripping using membrane contactors provides a number of advantages. These include a larger interfacial area per unit volume, which provides fast removal of the volatile contaminant, and independent control of gas and liquid flow rates without causing any flooding, loading, or foaming. This also contributes to lower capital cost and ease of operation [10]. In particular, ammonium can be recovered in the form of ammonium salt in liquid/liquid membrane contactor systems. Due to the increase of global demand for nitrogenous fertilizer, from $10 \mathrm{Mt} \mathrm{N}$ in 1960 to $90 \mathrm{Mt} \mathrm{N}$ in 1998 [11], control over the point sources of $\mathrm{N}$ and $\mathrm{P}$ has shifted from removal to recovery, with a particular emphasis on improving the sustainability of agricultural activities.

In this study, polytetrafluoroethylene (PTFE) membranes were used in order to contact the aqueous solutions of ammonia and the receiving solution. Diluted solutions of sulfuric acid

Received January 12, 2012 Accepted May 22, 2012

cc This is an Open Access article distributed under the terms of the Creative Commons Attribution Non-Commercial License (http://creativecommons. org/licenses/by-nc/3.0/) which permits unrestricted non-commercial use, distribution, and reproduction in any medium, provided the original work is properly cited.
${ }^{\dagger}$ Corresponding Author

E-mail: crista@kaist.ac.kr

Tel: +82-42-350-5653 Fax: +82-42-350-3610 


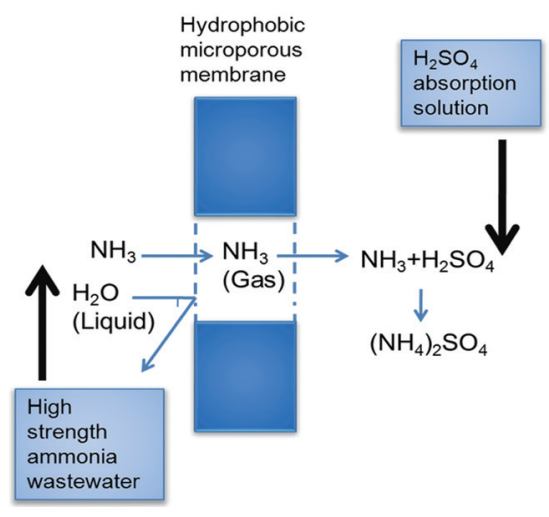

Fig. 1. Principle of ammonia removal in membrane contactor system.

were used as the receiving solution. The principle of the removal of the ammonia from the feed to the receiving solution is illustrated in Fig. 1. The hydrophobic membrane separates two circulating phases: the feed that is aqueous phase containing ammonia on the shell side and the receiving solution, and a diluted solution of sulfuric acid on the lumenside. An air gap fills the pores of the hydrophobic membrane, which is not wetted by the aqueous solutions.

First, ammonia $\left(\mathrm{NH}_{3}\right)$ diffuses from the bulk of the feed to the feed-membrane interface. $\mathrm{NH}_{3}$ volatilizes through the feedmembrane interface, diffuses across the air-filled pores of the membrane, and finally reacts immediately with sulfuric acid on the interface to form the non-volatile compound ammonium sulphate $\left(\left(\mathrm{NH}_{4}\right)_{2} \mathrm{SO}_{4}\right)$. Thus, the concentration of ammonia in the receiving solution is essentially zero. Total ammonia removal could be theoretically possible under this configuration, since the driving force for this liquid-gas-liquid membrane contactor operation is the difference in ammonia partial pressure between the feed and the receiving solution.

In this study, a tubular type membrane configuration was applied for ammonia stripping, and the feasibility of this membrane configuration was studied. The ammonia removal efficiencies under various operation conditions were evaluated. The $\mathrm{pH}$, initial ammonia concentration, flow rate, and temperature difference were selected as reaction variables, and the crucial factors for operation were evaluated.

\section{Materials and Methods}

\subsection{Synthesis and Characterization of NZVI}

In this research, the mild chemical reduction of metal salts in a solution phase, which had chemical homogeneity as a key advantage, was used to prepare NZVI [12]. The NZVI was synthesized in a $500 \mathrm{~mL}$ flask reactor with four open necks. One of the necks was housed with a tunable mechanical stirrer at 60 to 500 rpm. For the reduction of ferric ions to NZVI, a dropping funnel was used (at a rate of $1 \mathrm{drop} / \mathrm{sec}$ ) to introduce $250 \mathrm{~mL}$ of borohydride solution ( $358.4 \mathrm{mM}$ ) into $250 \mathrm{~mL}$ of ferric ion $\left(\mathrm{Fe}^{3+}\right)$ solution (71.7 $\mathrm{mM})$. The reduction reaction is expressed as follows [5]:

$$
4 \mathrm{Fe}^{3+}+3 \mathrm{BH}_{4}^{-}+9 \mathrm{H}_{2} \mathrm{O} \rightarrow 4 \mathrm{Fe}^{0}+3 \mathrm{H}_{2} \mathrm{BO}_{3}^{-}+12 \mathrm{H}^{+}+6 \mathrm{H}_{2}
$$

The NZVI was collected by centrifugation of the solution after

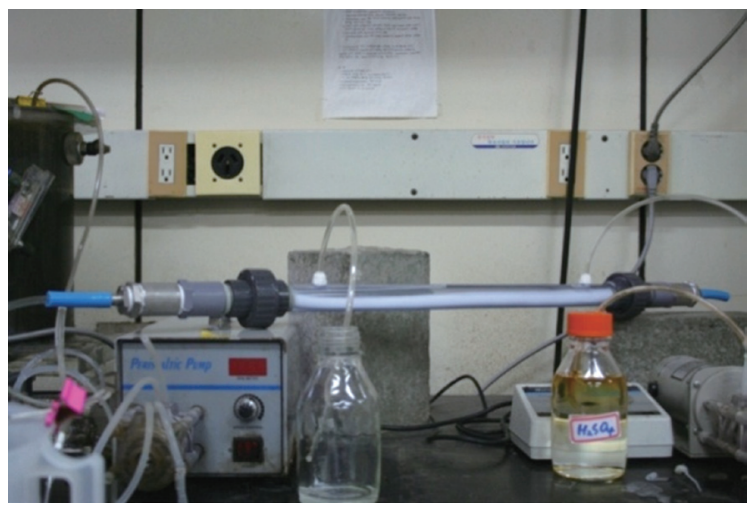

Fig. 2. Lab scale membrane contactor system for ammonia removal.

$20 \mathrm{~min}$ of aging. The collected particles were then washed three times with a large amount of degassed deionized water. The prepared NZVI was immediately used for a batch experiment. The NZVI was characterized with the help of a transmission electron microscope (TEM, Tecnai F20; Philips Electronics Co., Eindhoven, Netherlands), a particle size analyzer (ELS-8000; Otsuka Electronics Co., Osaka, Japan) and a Brunauer Emmett Teller (BET) surface area analyzer (Sorptomatic 1990; Thermo Fisher Scientific Inc., Waltham, MA, USA).

\subsection{Nitrate Reduction by NZVI}

Batch tests for nitrate reduction were conducted in $1 \mathrm{~L}$ Schlenk flasks. The reactor was filled with $700 \mathrm{~mL}$ of nitrate solution, and the solution was purged with argon gas before the injection of NZVI. Then, $100 \mathrm{~mL}$ of an NZVI slurry containing $1 \mathrm{~g}$ of NZVI was added to the reactor, which contained $100 \mathrm{mg} / \mathrm{L}$ of nitrate. The solution was continuously stirred with a mechanical stirrer. Samples were taken periodically, filtered with $0.45 \mu \mathrm{m}$ syringe filters, and then analyzed immediately. Argon gas was blown continually into the reactor to maintain an anoxic condition during the reaction.

Nitrate and nitrite concentrations were analyzed by means of ion chromatography (DX-120; Dionex Co., Sunnyvale, CA, USA). Ammonium and total nitrogen were analyzed using a standard method (ASTM D1426-03) and a spectrophotometer (DR-2010; $\mathrm{HACH}$, Loveland, CO, USA) in accordance with the guidelines of the 20th edition standard method.

\subsection{Membrane Contactor Configuration}

The tubular membrane used was made with PTFE and pore diameters of $0.4 \mu \mathrm{m}$, and $205.5 \mathrm{~cm}^{2}$ of effective surface area. The speciation of the membrane module is presented in Table 1.

Table 1. The speciation of membrane contactor module

\begin{tabular}{lc}
\hline Material & Polytetrafluoroethylene \\
\hline Nominal pore size $(\mu \mathrm{m})$ & 0.4 \\
Length $(\mathrm{cm})$ & 54.5 \\
Diameter (membrane, $\mathrm{cm})$ & 1.2 \\
Diameter (shell, cm) & 2.4 \\
Effective surface area $\left(\mathrm{cm}^{2}\right)$ & 205.5 \\
\hline
\end{tabular}



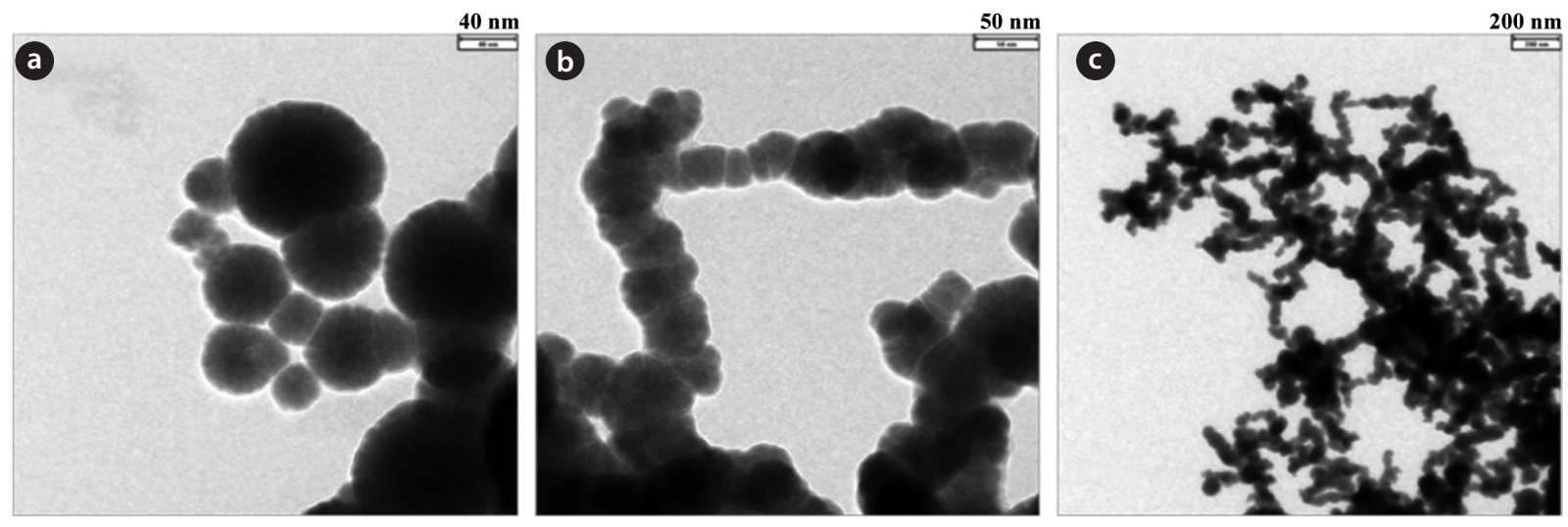

Fig. 3. Transmission electron microscope images of the prepared nanoscale zero-valent iron with different magnification.

Fig. 2 shows the membrane contactor system used in this study. The membrane module consists of PTFE tubular membrane encased in a polypropylene (PP) pressure vessel. The substrates were fed to the inside of membrane and the strip solution was supplied on the shell-side. Sulfuric acid $(10 \%$, w/w) was used as a stripping solution and flowed in the opposite direction of feed solution.

\subsection{Operation Conditions of Membrane Contactor}

The feasibility of a membrane contactor to remove produced ammonia was evaluated under different operating conditions. Influent $\mathrm{pH}$ was selected to figure out the effect of free ammonia fraction on ammonia removal. The effect of initial ammonia concentration ( 250 and $1,000 \mathrm{mg} / \mathrm{L}$ ), flow rate of feed solution (10 and $20 \mathrm{~mL} / \mathrm{min}$ ) and strip solution ( 8 and $16 \mathrm{~mL} / \mathrm{min}$ ), and temperature difference between feed and strip solution $\left(0^{\circ} \mathrm{C}\right.$, $13^{\circ} \mathrm{C}$ ) were also evaluated. The specific experimental conditions are shown in Table 2.

\subsection{Ammonia Removal Kinetics}

The change of ammonia concentration with time was used to calculate the overall mass transfer coefficient $\left(\mathrm{k}_{\mathrm{m}}\right)$ as follows [13]:

$$
\ln \frac{C_{0}}{C}=\frac{Q_{t}}{V}\left(1-e^{-\frac{k \alpha L}{v}}\right)
$$

in which $\mathrm{C}_{0}$ is the initial total ammonia concentration, $Q$ is the total flow through the module, $t$ is the time, $V$ is the total volume of ammonia solution, and $a, L$, and $v$ are the area per vol- ume, the membrane length, and the feed velocity in the module, respectively. Eq. (1) was derived from mass balances of the module and the ammonia solution, assuming that the acid reservoir is big enough to neutralize all the ammonia.

\section{Results and Discussion}

\subsection{Properties of NZVI and Its Nitrate Reduction Capability}

The TEM morphologies of the prepared NZVI in this study are shown in Fig. 3 with different magnifications. Laser scattering particle size analysis shows that the average diameter of the prepared NZVI was $16.7 \mathrm{~nm}$. The BET surface area was $79.06 \mathrm{~m}^{2} / \mathrm{g}$.

As shown in Fig. 3(c), NZVI is spherical with a chain network structure. The spherical shape and chain net morphology are similar to those observed in other studies [14]. The aggregation of NZVI in aqueous solution without a surfactant is a common behavior, but the accessibility of reactants to NZVI is good because the total surface area is unaffected due to the high porosity of the aggregates $[15,16]$. The high reaction rate expected was confirmed by the high nitrate reduction rate of the subsequent experiments.

Fig. 4 shows the profile of aqueous nitrogen species in relation to the reaction time during nitrate reduction by NZVI. The reference conditions were a temperature of $30^{\circ} \mathrm{C}$, an initial $\mathrm{pH}$ of 7 , and an unbuffered status. More than $97 \%$ of the nitrate was removed within $1 \mathrm{hr}$ and complete removal was obtained within $1.5 \mathrm{hr}$. Ammonia was produced as the main by-product, and its concentration decreased after $1 \mathrm{hr}$ of reaction. Therefore, the suitable reaction time for the highest ammonia recovery is $1 \mathrm{hr}$.

Table 2. The experimental conditions

\begin{tabular}{|c|c|c|c|c|c|c|}
\hline & $\mathrm{NH}_{3 \text { in }}$ & SS & $\Delta \mathrm{T}\left({ }^{\circ} \mathrm{C}\right)$ & $\mathrm{Q}_{\mathrm{feed}}(\mathrm{mL} / \mathrm{min})$ & $\mathrm{Q}_{\text {strip }}(\mathrm{mL} / \mathrm{min})$ & Variable \\
\hline Set 1 & 250 & 0 & 0 & 10 & 8 & Influent $\mathrm{NH}_{3}-\mathrm{N}$ \\
\hline Set 2 & 1,000 & 0 & 0 & 10 & 8 & \\
\hline Set 3 & 1,000 & 0 & 13 & 10 & 8 & Temperature \\
\hline Set 4 & 1,000 & 0 & 0 & 20 & 8 & Flow condition \\
\hline Set 5 & 1,000 & 0 & 0 & 10 & 16 & \\
\hline
\end{tabular}

SS: suspended solid. 


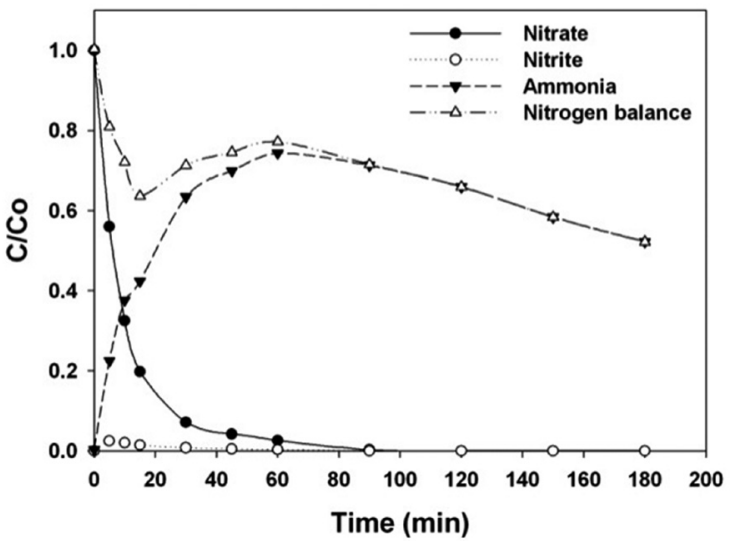

Fig. 4. Nitrate reduction profile by nanoscale zero-valent iron.

\subsection{Ammonia Stripping under Various $\mathrm{pH}$ and Its Related Kinetics}

\subsubsection{Effects of $\mathrm{pH}$ on ammonia removal by membrane contactor}

For efficient removal of ammonia, it should be in its volatile form. Increasing $\mathrm{pH}$ or temperature to a point where all ammonium-nitrogen $\left(\mathrm{NH}_{4}{ }^{+}-\mathrm{N}\right)$ is in its volatile ammonia form $\left(\mathrm{NH}_{3}\right)$ ensures this. The expression for free ammonia (FA) fraction of the total reduced ammonia is derived from known equilibrium expressions and is presented in Eq. (2) [17].

$$
\mathrm{FA}=\frac{10^{\mathrm{pH}}}{\mathrm{e}^{\frac{6244}{273.15}}+10^{\mathrm{pH}}}
$$

At constant temperature, $\mathrm{pH}$ is the one factor that influences FA fraction. Therefore, $\mathrm{pH}$ is one of the most important factors determining overall reaction efficiency. According to Eq. (2), high ammonia removal rate is expected at high $\mathrm{pH}$. The ammonia removal rate is shown in Fig. 5(a). The ammonia removal rate was increased with the increased free ammonia fraction in the feed solution in the $\mathrm{pH}$ range of 7 to 11 . Therefore, it was concluded that the high $\mathrm{pH}$ of the feed solution was essential for effective ammonia stripping. All of following batch experiments were performed at $\mathrm{pH} 11$ based on this preliminary test.

As shown in Fig. 5(b), the $\mathrm{pH}$ was increased to 10.5 during the nitrate reduction. The free ammonia fraction was $54.2 \%$ under $\mathrm{pH} 10$. Therefore, it was possible to remove the produced ammonia effectively by the membrane contactor without $\mathrm{pH}$ adjustment.

3.2.2. Effects of influent concentration on mass transfer coefficient

Biological processes can be applied to remove ammonia and other contaminants from water and wastewater. However, the high concentration of ammonia has inhibitory effects on biological wastewater treatment processes. By using the membrane contactor, which is one of the conventional physico-chemical processes, selective dissolved pollutants can be removed. The ammonia removal kinetic described in Section 2.3 is not a function of concentration, but of residual fraction. To verify the effect of influent concentration on membrane contactor operation, the ammonia removal rate was observed at different initial ammonia concentrations of 250 and $1,000 \mathrm{mg} / \mathrm{L}$.

The amount of removed ammonia was increased with increased influent ammonia concentration in Fig. 6(a). However, the trend of residual fraction does not have a significant difference with different concentration. The mass transfer coefficient $\left(\mathrm{k}_{\mathrm{m}}\right)$ decreased from $7.25 \times 10^{-3} \mathrm{~m} / \mathrm{hr}$ to $7.0 \times 10^{-3} \mathrm{~m} / \mathrm{hr}(3.4 \%)$ as the ammonia concentration increased from 250 to $1,000 \mathrm{mg} / \mathrm{L}$. These results indicate the ammonia removal is mainly controlled by the ratio of ammonia concentration in the feed and strip solutions. Therefore, the membrane contactor is a suitable process for high strength wastewater.

\subsection{Enhancement of Ammonia Stripping Efficiency by Changing of Temperature \& Hydraulic Conditions}

\subsubsection{Prevention of osmotic distillation}

Osmotic distillation (OD) is an evaporative membrane contractor process, which is a coupled process in membrane absorption in treating high-strength ammonia-containing wastewater [18]. Due to the difference of vapour pressure between feed stream and strip solution stream, water molecules leak from the feed solution into the strip solution through membrane pores. (Fig. 7)
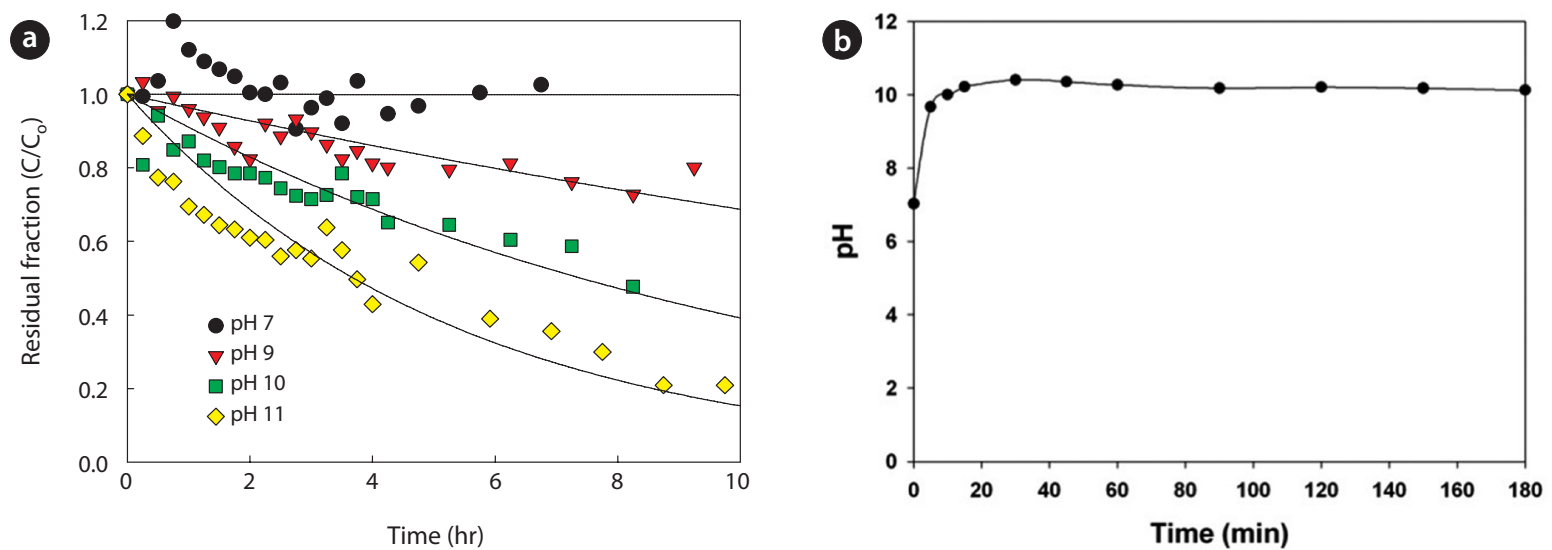

Fig. 5. (a) Ammonia removal time profile at various solution $\mathrm{pH}$ conditions, (b) $\mathrm{pH}$ variation during nitrate reduction by nanoscale zero-valent iron. 

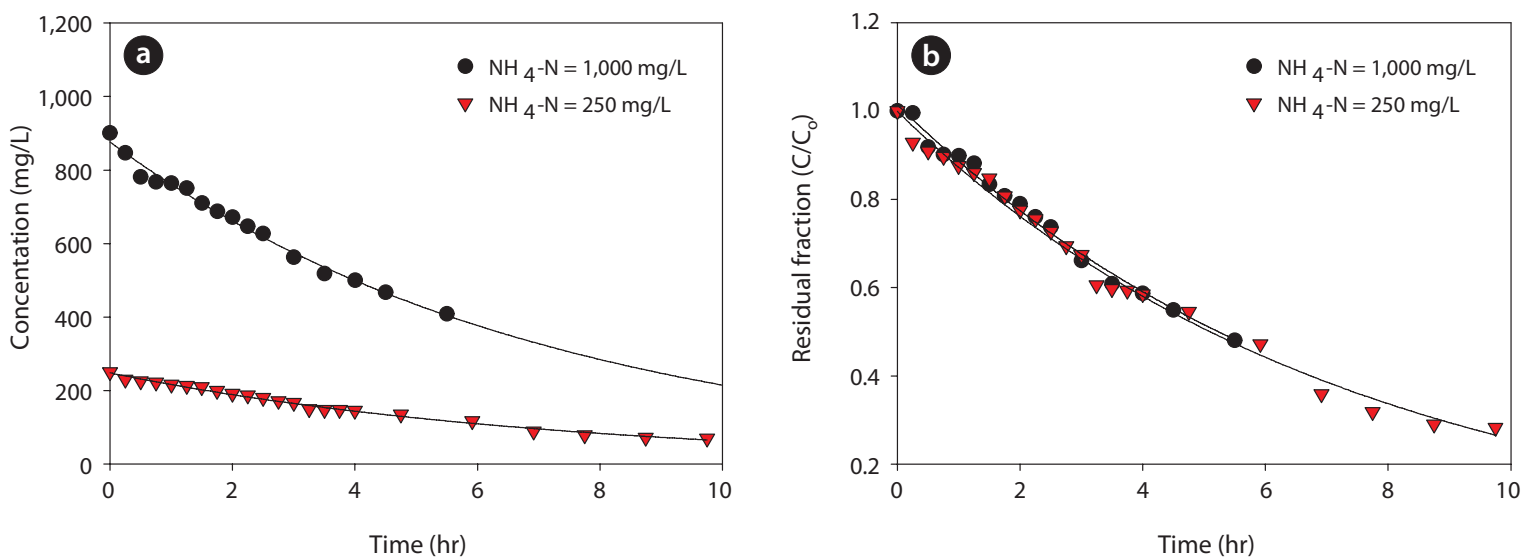

Fig. 6. Effect of initial concentration on ammonia removal in the membrane contactor; (a) concentration, (b) residual fraction.

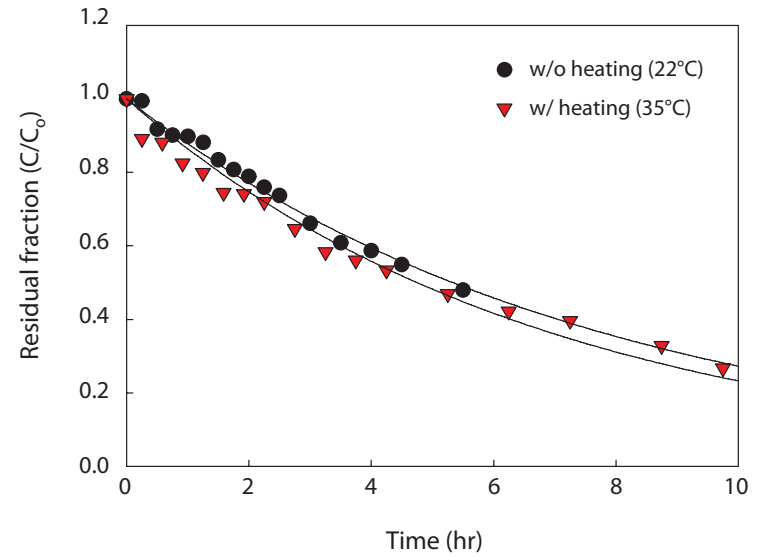

Fig. 7. Effect of operating temperature on ammonia removal in the membrane contactor.

It was clear that the coupled OD brought negative effects to ammonia removal in the membrane contactor system. The removed ammonia could not be concentrated in the strip solution effectively due to the undesired transfer of water molecules by the osmotic distillation phenomenon. Therefore, the OD effects should be minimized to ensure successful operation of the membrane contactor process. Pre-heating of feed solution is one of the possible solutions to minimize the OD effect. Due to the high vapor pressure of the heated strip solution, water could not pass through the membrane from the feed solution. To verify this theory, strip solution was heated to $35^{\circ} \mathrm{C}$, which was selected as the model temperature in mesophilic conditions (feed solution,

Table 3. The effect of osmotic distillation in membrane contactor operation

\begin{tabular}{cccc}
\hline & $\begin{array}{c}\text { Initial volume } \\
(\mathrm{mL})\end{array}$ & $\begin{array}{c}\text { Final volume } \\
(\mathrm{mL})\end{array}$ & $\begin{array}{c}\text { Volume change } \\
(\mathrm{mL})\end{array}$ \\
\hline Control & 940 & 965 & +25 \\
Heating & 940 & 930 & -10 \\
\hline
\end{tabular}

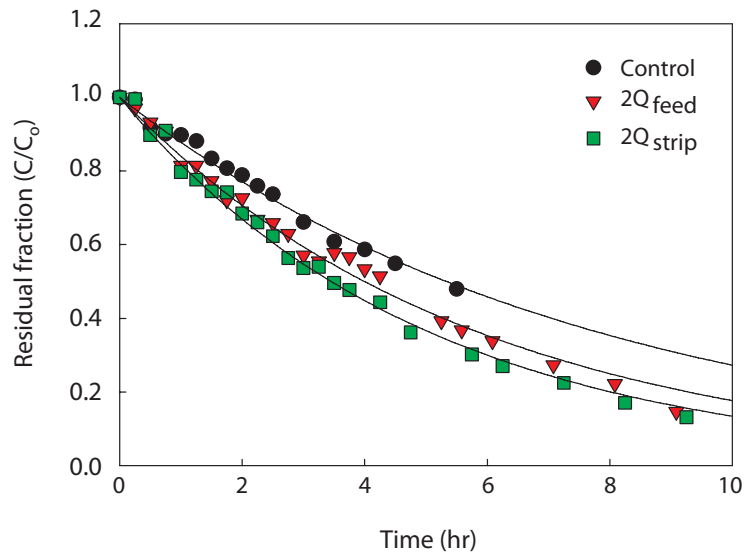

Fig. 8. Effects of feed and stripping solution flow rate on ammonia removal in the membrane contactor.

$22^{\circ} \mathrm{C}$ ). Because of the temperature difference, the ammonia removal rate increased to $7.3 \times 10^{-3} \mathrm{~m} / \mathrm{hr}(4.4 \%)$. This result indicated that the effect of osmotic distillation on ammonia removal was not significant. (Table 3)

In case of the control experiment, the volume of feed solution increased by osmotic distillation phenomena. On the other hand, the volume of feed solution decreased in case of heating. Therefore, the osmotic distillation phenomenon was suppressed by temperature increase, even though it was not significant.

\subsubsection{Increase of flow rate}

A large surface area of the membrane module can guarantee successful removal of ammonia in the membrane contactor system since the ammonia removal mechanism is evaporation through the membrane pores. Operation with high flow rate is one of the alternative ways to increase the contact between the strip solution and the wastewater stream. The flow rate was increased to twice that in control experiments for both of feed solution and strip solution.

As the flow rate increased for both solutions, the ammonia removal efficiency increased slightly, as shown in Fig. 8. Particularly, increase of strip solution flow rate showed great enhance- 
Table 4. Summary of mass transfer coefficient under various operating conditions

\begin{tabular}{|c|c|c|c|c|c|c|}
\hline & $\mathrm{NH}_{3 \text { in }}$ & SS & $\Delta \mathrm{T}\left({ }^{\circ} \mathrm{C}\right)$ & $Q_{\text {feed }}(\mathrm{mL} / \mathrm{min})$ & $\mathrm{Q}_{\text {strip }}(\mathrm{mL} / \mathrm{min})$ & $\begin{array}{l}\text { Mass transfer coefficient. } \\
\qquad\left(\times 10^{-3} \mathrm{~m} / \mathrm{hr}\right)\end{array}$ \\
\hline \multirow[t]{2}{*}{ Influent $\mathrm{NH}_{3}-\mathrm{N}$} & 250 & 0 & 0 & 10 & 8 & 7.3 \\
\hline & 1,000 & 0 & 0 & 10 & 8 & 7.0 \\
\hline Temperature & 1,000 & 0 & 13 & 10 & 8 & 7.3 \\
\hline \multirow[t]{2}{*}{ Flow condition } & 1,000 & 0 & 0 & 20 & 8 & 9.7 \\
\hline & 1,000 & 0 & 0 & 10 & 16 & 11.0 \\
\hline
\end{tabular}

SS: suspended solid.

ment of ammonia removal rate. This might be due to the strip solution being saturated at low flow rate. Therefore, the supply of fresh strip solution and high membrane surface area were essential for efficient membrane contactor operation.

The mass transfer coefficients under various operation conditions are summarized in Table 4. The mass transfer coefficient increased with the low influent ammonia concentration, suspended solid-free condition, suppression of osmotic distillation by temperature difference, and high flow rate for both strip and feed streams. Among these various operation conditions, higher flow rate led to greatest enhancement of mass transfer. This means that the most important factor for efficient ammonia removal in membrane contactors is the contact time, which could also be attained by the use of membranes with large surface areas. Because a tubular membrane module was applied in this study, it is hard to increase the membrane surface area. Alternatively, operation at high flow rate could be considered for effective ammonia removal.

\section{Conclusions}

In this research, complete removal and recovery of nitrate was studied by a combination of NZVI and a membrane contactor system. Ammonia was produced as the main end product of nitrate reduction by NZVI, and the produced ammonia was effectively removed in the tubular PTFE membrane contactor system. The removal efficiency of ammonia removal was mainly affected by feed solution $\mathrm{pH}$. The solution $\mathrm{pH}$ of nitrate reduction by NZVI was maintained over 10, which is suitable for ammonia recovery by the membrane contactor. The effect of various operating conditions including influent ammonia concentration, temperature, and flow rate were investigated for the enhancement of mass transfer in the membrane contactor system. Among the various operation conditions, flow rate showed the most critical impact on ammonia removal by increasing the mass transfer coefficient over $50 \%$. The ammonia removal rate can be maximized by optimizing operation conditions and changing membrane configuration. Therefore, the combination of NZVI and the membrane contactor system could be a solution for nitrate removal and recovery of valuable products.

\section{References}

1. Hatfield JL, Follett RF. Nitrogen in the environment: sources, problems, and management. New York: Academic Press; 2001. p. 17-44.

2. Bae BU, Jung YH, Han WW, Shin HS. Improved brine recycling during nitrate removal using ion exchange. Water Res.
2002;36:3330-3340

3. Bohdziewicz J, Bodzek M, Wassik E. The application of reverse osmosis and nanofiltration to the removal of nitrates from groundwater. Desalination 1999;121:139-147.

4. Soares MI. Biological denitrification of groundwater. Water Air Soil Pollut. 2000;123:183-193.

5. Zhang TC, Huang YH. Effects of selected good's pH buffers on nitrate reduction by iron powder. J. Environ. Eng. 2005;131:461-470.

6. Choe SH, Hwang KY, Chang YY, Khim JH. The Rapid denitrification of nitrate-polluted water by synthesized nanoscale iron particles. Environ. Eng. Res. 2001;6:1-6.

7. Hwang YH, Kim DG, Ahn YT, Moon CM, Shin HS. Fate of nitrogen species in nitrate reduction by nanoscale zero valent iron and characterization of the reaction kinetics. Water Sci. Technol. 2010;61:705-712.

8. Baker RW. Membrane technology and applications. 2nd ed. New York: John Wiley \& Sons; 2004.

9. Park HH, Deshwal BR, Jo HD, Choi WK, Kim IW, Lee HK. Absorption of nitrogen dioxide by PVDF hollow fiber membranes in a G-L contactor. Desalination 2009;243:52-64.

10. Drioli E, Criscuoli A, Curcio E. Membrane contactors: fundamentals, applications and potentialities. Amsterdam: Elsevier; 2006.

11. Mulder A. The quest for sustainable nitrogen removal technologies. Water Sci. Technol. 2003;48:67-75.

12. Wang CB, Zhang WX. Synthesizing nanoscale iron particles for rapid and complete dechlorination of TCE and PCBs. Environ. Sci. Technol. 1997;31:2154-2156.

13. Semmens MJ. Ammonia removal from water using microporous hollow fibers. J. Membr. Sci. 1990;51:127-140.

14. Wang W, Jin ZH, Li TL, Zhang H, Gao S. Preparation of spherical iron nanoclusters in ethanol-water solution for nitrate removal. Chemosphere 2006;65:1396-1404.

15. Yang GC, Lee HL. Chemical reduction of nitrate by nanosized iron: kinetics and pathways. Water Res. 2005;39:884-894.

16. Wu L, Shamsuzzoha M, Ritchie SM. Preparation of cellulose acetate supported zero-valent iron nanoparticles for the dechlorination of trichloroethylene in water. J. Nanoparticle Res. 2005;7:469-476.

17. Du Preez J, Norddahl B, Christensen K. The BIOREK concept: a hybrid membrane bioreactor concept for very strong wastewater. Desalination 2005;183:407-415.

18. Wang GP, Shi HC, Shen ZS. Influence of osmotic distillation on membrane absorption for the treatment of high strength ammonia wastewater. Proceedings of the IWA International Specialty Symposium on Strong Nitrogenous and AgroWastewater; 2003 Jun 11-13; Seoul, Korea. London: International Water Association; 2003. 